\title{
Long-Term Mechanical Insufflation-Exsufflation Cough Assistance in Neuromuscular Disease: Patterns of Use and Lessons for Application
}

\author{
Michelle Chatwin and Anita K Simonds
}

\begin{abstract}
BACKGROUND: Mechanical insufflation-exsufflation (MI-E) devices increase expiratory air flow and thereby promote increased cough peak flow (CPF) in conjunction with a cough. There is little research looking at long-term use of MI-E in subjects with neuromuscular disease (NMD), and no long-term study has reported CPF, MI-E device settings, and adherence. METHODS: We evaluated 181 patient records (130 adults, 51 children) of individuals who received a MI-E device from our center between February 2014 and February 2018. Median age (interquartile range [IQR]) was 27 (14-51) y. Duchenne muscular dystrophy (DMD), spinal muscular atrophy (SMA), and amyotrophic lateral sclerosis (ALS) were the 3 most common diagnoses. RESULTS: MI-E devices were provided to the weakest subjects with a CPF $<160 \mathrm{~L} / \mathrm{min}$. Median (IQR) settings were insufflation, 25 (23-30) $\mathrm{cm} \mathrm{H}_{2} \mathrm{O}$, exsufflation $-35(-30$ to -40$) \mathrm{cm}_{2} \mathrm{O}$, insufflation time $1.5(1.3-1.7) \mathrm{s}$, exsufflation time $1.8(1.5-2.0) \mathrm{s}$, and pause $1.5(1.3-2.0) \mathrm{s}$. The inspiratory flow profile was set to high in all subjects, and no subject used supplemental oxygen with the MI-E device. When comparing insufflation pressures to exsufflation pressures, a greater negative pressure was used relative to positive pressure $(P<.001)$. When comparing insufflation to exsufflation time, there was a significantly longer exsufflation duration $(P<.001)$. Median $($ IQR) CPF at the start of MI-E was 60 (10-100) $\mathrm{L} / \mathrm{min}$. There was no correlation between either insufflation or exsufflation pressures and CPF. Median (IQR) usage for the group was $60 \%(13.5-100 \%)$ of days for the total days. Subjects with tracheostomies or SMA type I had the greatest adherence to treatment. Median (IQR) duration of MI-E use was 17 (8.5-32) months. Ninety-six percent of subjects were receiving ventilatory support. CONCLUSIONS: Greater exsufflation pressures than insufflation pressures, together with a shorter insufflation time than exsufflation time, were used. Predicting good adherence among the subjects was difficult. Subjects who produced daily secretions were more likely to use MI-E every day. Key words: cough assist; ineffective cough; airway clearance techniques; neuromuscular disease; home care. [Respir Care 2020;65(2):135-143. (C) 2020 Daedalus Enterprises]
\end{abstract}

\section{Introduction}

The aim of a mechanical insufflation-exsufflation (MI-E) device is to increase expiratory air flow and thereby promote, in conjunction with a cough, increased cough peak flow (CPF). By increasing $\mathrm{CPF}$, secretions move more efficiently to the central airways to be cleared from the

\footnotetext{
Drs Chatwin and Simonds are affiliated with the Academic and Clinical Department of Sleep and Breathing, Royal Brompton \& Harefield NHS Foundation Trust, Sydney Street, London, United Kingdom.

Dr Chatwin discloses relationships with B\&D Electromedical, ResMed, Phillips, and Breas Medical. Dr Simonds discloses a relationship with ResMed.
}

mouth or an artificial airway. Two recent publications by an international panel of experts in this area concluded that MI-E is an expensive but "ideal" technique to assist cough in individuals severely affected by neuromuscular disease (NMD). ${ }^{1,2}$ They also produced recommendations for individuals over the age of 12 years based on the available evidence of which cough-augmentation technique would be most effective, depending on the individual's CPF. MI-E

\footnotetext{
Correspondence: Michelle Chatwin PhD, Academic and Clinical Department of Sleep and Breathing, Royal Brompton Hospital, Sydney Street, London, SW3 6NP, United Kingdom. E-mail: m.chatwin@rbht.nhs.uk.
}

DOI: $10.4187 /$ respcare. 06882 
devices are recommended in individuals with a $\mathrm{CPF} \leq$ $160 \mathrm{~L} / \mathrm{min}^{1}$

\section{See the Related Editorial on Page 265}

Despite there being recommendations for commencing MI-E when $\mathrm{CPF}$ is $<160 \mathrm{~L} / \mathrm{min},{ }^{1,3-6}$ there are no such recommendations for optimum settings in patients with NMD. Bench studies have shown that high insufflation and exsufflation pressures $\left(+50 \mathrm{~cm} \mathrm{H}_{2} \mathrm{O}\right.$ to $\left.-50 \mathrm{~cm} \mathrm{H}_{2} \mathrm{O}\right)$ are required to produce effective peak expiratory flows from artificial aiways. $^{7}$ In a pediatric lung model, an insufflation time of $>1 \mathrm{~s}$ was required for equilibrium between insufflation pressure and alveolar pressure. ${ }^{8}$ Higher insufflation and exsufflation pressures both increased expiratory flow, but greater exsufflation pressure had a more substantial impact on mean expiratory flow. ${ }^{8}$ Long exsufflation times did not improve expiratory flow. In an adult lung model, high pressures $(+40$ to $-40 \mathrm{~cm} \mathrm{H}_{2} \mathrm{O}$ ), with an insufflation time of $3 \mathrm{~s}$ and an exsufflation time of $2 \mathrm{~s}$, were required to generate an exsufflation flow of $294 \mathrm{~L} / \mathrm{min} .^{9}$ The authors concluded that increasing insufflation time more than exsufflation time was more important for optimum effect. A recent study found that mucus transport could be further enhanced by applying a slow insufflation, which created a greater expiratory flow bias. ${ }^{10}$ Despite this evidence base, some centers reported an increase in CPF with low pressures, ${ }^{11-14}$ whereas others have reported efficacy with high pressures. ${ }^{15-20}$ Hov and coworkers $^{21}$ surveyed centers in Europe and found that younger children were set up with lower MI-E pressures than older children and that there was wide variation in settings prescribed. There has only been one study, a small survey of 37 subjects, to report that $<50 \%$ of subjects with an MI-E device used it daily. ${ }^{22}$ Optimum MI-E adherence in this group remains unknown.

Based on the British Thoracic Society Guidelines, ${ }^{3,4}$ subjects at the Royal Brompton Hospital were assessed for MI-E and other cough-augmentation techniques. MI-E was considered as a treatment option in subjects who had experienced recurrent respiratory tract infections (ie, $>3$ in 12 months) and who remained unable to increase CPF to $>160 \mathrm{~L} / \mathrm{min}$ with other cough-augmentation strategies. MI-E was considered in children (ie, $<12$ y old) with recurrent respiratory tract infections when CPF was $<50 \%$ of predicted. ${ }^{23}$

There are no large reports of service provision for longterm use, safety, downloaded adherence, discontinuation rate, and prescription details of MI-E; such reports could inform clinical practice. We report our subject group with regard to $\mathrm{CPF}$ at initiation of $\mathrm{MI}-\mathrm{E}$, adherence to treatment recommendations, safety, settings, and discontinuation of MI-E.

\section{QUICK LOOK}

\section{Current knowledge}

Mechanical insufflation exsufflation (MI-E) devices improve cough efficacy. In children receiving home MI-E, wide variations in the settings prescribed and in adherence have been reported. No studies have reported longterm use with respect to adherence and safety.

\section{What this paper contributes to our knowledge}

Long-term use of MI-E was safe in subjects with neuromuscular disease with few side effects. Individualized settings and management plans were applied considering each subject's age and diagnosis. Greater exsufflation pressures than insufflation pressures were used. Adherence was variable; subjects with daily secretions or a tracheostomy were more likely to use MI-E daily.

\section{Methods}

See Figure 1 for subject flow process. Where possible, subjects performed an unassisted CPF. Subjects were asked to take a deep breath in and then cough into a pediatric flow meter (Pediatric Low Flow Wright Mini Peak Flow Meter, Clement Clarke, Harlow, Essex, United Kingdom) attached to a QuadraLite anesthetic full face mask (Intersurgical, Wokingham, Berks, United Kingdom). This measurement was repeated at least 6 times, and the best result was recorded. ${ }^{1,2}$

The Research Services team was contacted at the Royal Brompton Hospital to determine whether ethical approval was required for the project. All data were anonymized for analysis. The project was deemed to be service development and an evaluation project. This was registered on the clinical audit database (CIRIS for Healthcare, Project ID 001566).

\section{Inclusion and Exclusion Criteria}

Inclusion criteria were all adults and children with NMD who fulfilled criteria for MI-E use. Exclusion criteria were undrained pneumothorax present prior to initiation, pneumomediastinum, tracheoesophageal fistula, severe facial deformity, unstable upper airway, epistaxis, severe gastroesophageal reflux with risk of aspiration, severe esophageal and gastric varices, and inability to use a full face mask. No subject was excluded due to learning difficulties, severe bulbar impairment, or if they required nasopharyngeal or oropharyngeal suction. 


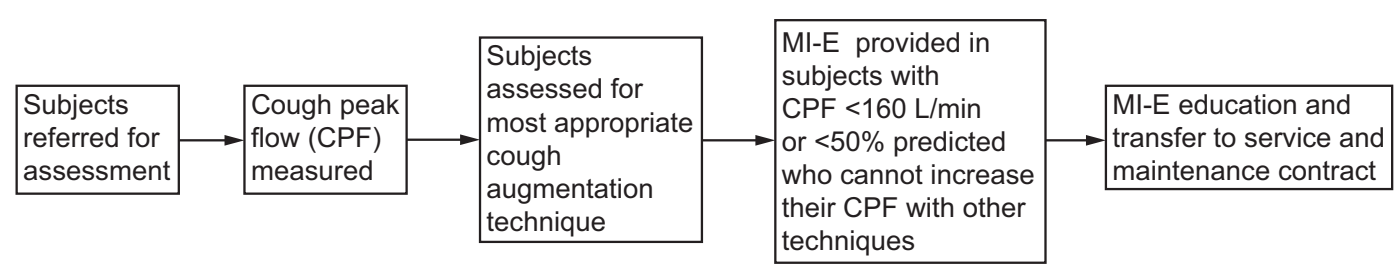

Fig. 1. Study diagram. MI-E = mechanical insufflation-exsufflation.

\section{MI-E Service Provision}

If MI-E was deemed to be appropriate, subjects were placed within our personalized MI-E home care service, which consists of a 24-h emergency contact number for patients to call if they have any problems with their device or consumables, or to call if their device breaks down or becomes faulty. Devices were exchanged within $24 \mathrm{~h}$ if broken or faulty. Yearly servicing and consumables were sent directly from the home care company to the subject on a quarterly basis. Overall the service was part of patients' standard National Health Service care package.

\section{MI-E Initiation}

The need for a MI-E device was assessed by the respiratory physiotherapist. The initiating respiratory physiotherapist was also responsible for ensuring that the subject and their carers were trained in using the device and reached a level of competence to be able to use the device effectively and safely. Subjects were started on MI-E in both the in-patient and out-patient settings. During the initiation session, the subject's oxygen levels were monitored with pulse oximetry. Resuscitation equipment was readily available in the event that an overwhelming volume of secretions could not be cleared with MI-E.

\section{Settings}

Subjects were initiated on MI-E as per our starting settings algorithm (Fig. 2). All subject prescriptions for MI-E were then individualized. We did not have a maximum insufflation pressure that could be set, although insufflation pressure was limited to prevent mask leak. Feedback was provided by the subject as to whether they subjectively felt their cough was stronger. An increase in cough audibility was also used as an indicator of improvement in cough strength because the device in use did not measure CPF. ${ }^{24}$ Settings were optimized by the physiotherapist and not the home care service and maintenance team. Any changes in prescription or subject details were updated with the home care service and the maintenance team to ensure an up-to-date accurate prescription, should a home visit or device exchange be required.

\section{Usage Recommendations}

Subjects were advised to use the device on a daily basis with 3 aims: to ensure familiarity with the device, to ensure their chest was clear, and to maintain chest wall compliance. Subjects were encouraged to let the device fill up their lungs and then deflate them. Subjects were recommended to cough with exsufflation only when secretions were in the central airways.

All subjects after January 1, 2013, were provided with an MI-E device (Nippy Clearway, Breas Medical, Stratford Upon Avon, Warks, United Kingdom) from our home care service and maintenance team. From our database we extracted subject demographics: sex, age at initiation, diagnosis, whether they were able to perform a CPF maneuver, unassisted CPF, vital capacity. We evaluated MI-E modes, settings, and interface (mask or tracheostomy). We also examined subject adherence over a 12-month period and the number and the nature of calls to the emergency line and to the home care service and maintenance team.

\section{Results}

A total of 181 subjects (130 adults, 51 children; $0-16$ y old; 115 male, 66 female) received a MI-E device between February 2014 and February 2018. Median (IQR) duration of MI-E use was 17 (8.5-32) months. Group median age (interquartile range [IQR]) was $27(14-51) \mathrm{y}$. Adults were defined as $>16$ y old, and the median age (IQR) was 33 (24-56) y. The median age (IQR) of pediatric subjects was $10(4-13) \mathrm{y}$. The youngest subjects were 9 months old. In subjects with Duchenne muscular dystrophy (DMD), median (IQR) age was $27(23-29) \mathrm{y}$; in subjects with spinal muscular atrophy (SMA), median (IQR) age was $14(8-20) y$, and in subjects with amyotrophic lateral sclerosis (ALS), median (IQR) age was $58(51-73)$ y old, which were the most common diagnoses. See Table 1 for full subject diagnoses.

Device mode, settings, and interface are shown in Table 2. Significantly higher exsufflation pressures were used compared to insufflation $(P<.001)$, along with a longer exsufflation to insufflation time $(P<.001)$ for all subjects. Settings for the most common diagnoses are shown 
Step 1: Insufflation pressure

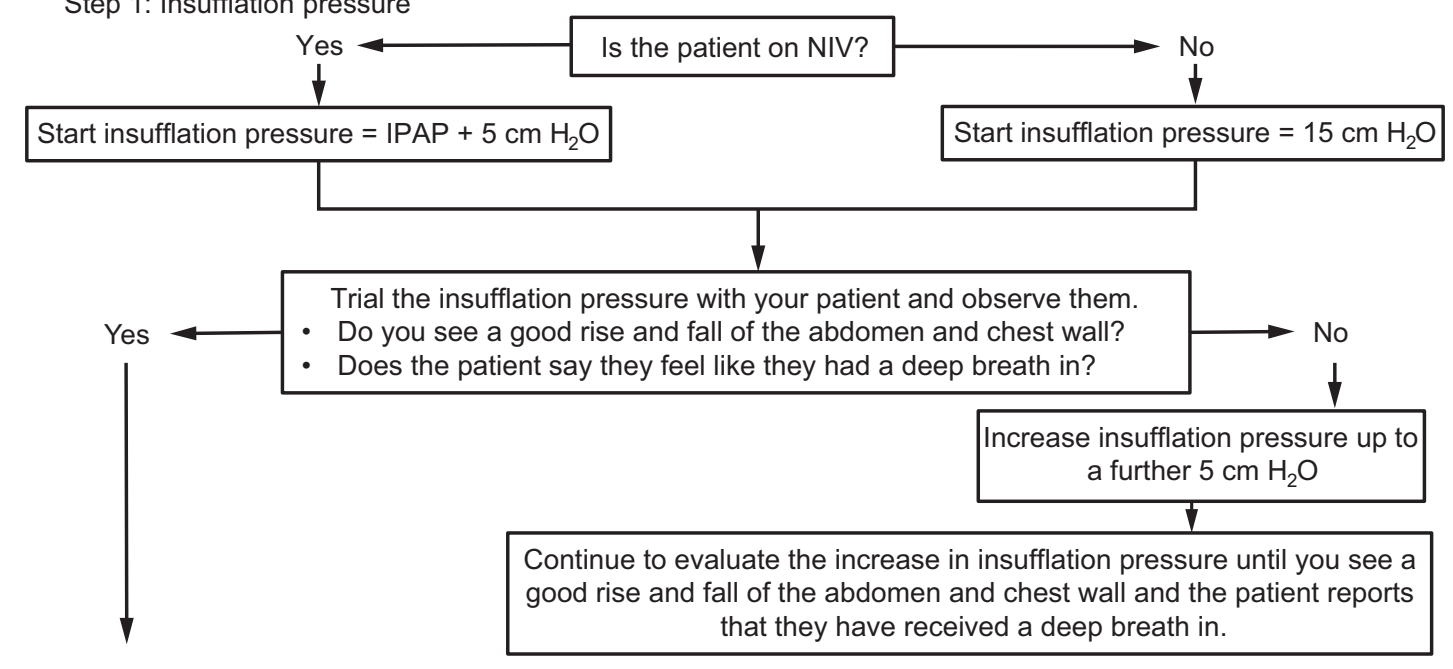

Step 2: Exsufflation pressure

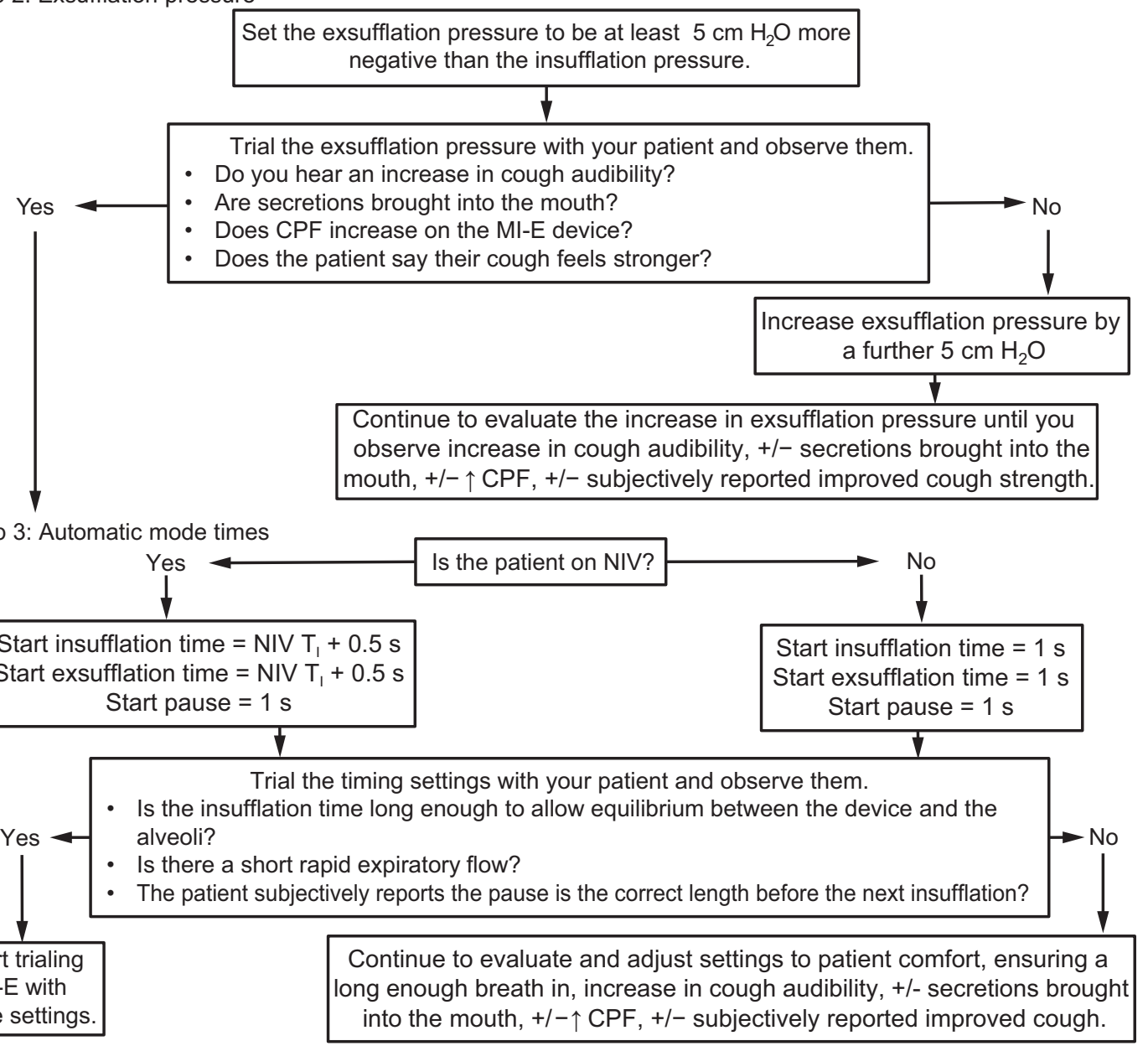

Fig. 2. Algorithm suggested for establishing MI-E settings showing a 3-step process for initiating the subject with an MI-E device based on the clinical experience from our center. It provides suggested starting points depending on whether the subject is using NIV. All settings should be individualized to the patient, and constant re-evaluation to optimize settings should occur with patient feedback. NIV = noninvasive ventilation; IPAP = inspiratory positive airway pressure; MI-E = mechanical insufflation-exsufflation; CPF = cough peak flow; $+/-=$ with or without; $\uparrow=$ increase; $\mathrm{T}_{1}=$ inspiratory time. 
Table 1. Subject Diagnosis

\begin{tabular}{|c|c|}
\hline \multicolumn{2}{|l|}{ Muscular dystrophy } \\
\hline Becker muscular dystrophy & $1(0.6)$ \\
\hline Congenital muscular dystrophy & $11(6.1)$ \\
\hline Duchenne muscular dystrophy & $39(22.5)$ \\
\hline Facioscapulohumeral muscular dystrophy & $3(1.7)$ \\
\hline \multicolumn{2}{|l|}{ Spinal muscular atrophy } \\
\hline Type 1 & $5(2.8)$ \\
\hline Type 2 & $24(13.3)$ \\
\hline Type 3 & $5(2.8)$ \\
\hline SMARD & $2(1.1)$ \\
\hline \multicolumn{2}{|l|}{ Amyotrophic lateral sclerosis } \\
\hline Bulbar & $9(5.0)$ \\
\hline Nonbulbar & $14(7.7)$ \\
\hline Unknown neuromuscular disease & $4(2.2)$ \\
\hline Post polio & $3(1.7)$ \\
\hline Myotonic dystrophy & $4(2.2)$ \\
\hline Congenital myasthenia syndrome & $1(0.6)$ \\
\hline Myopathy & $12(6.6)$ \\
\hline Spinal cord injury & $9(5.0)$ \\
\hline \multicolumn{2}{|l|}{ Neurological } \\
\hline Parkinson disease & $2(1.1)$ \\
\hline Neuropathy & $4(2.2)$ \\
\hline Multiple sclerosis & $3(1.7)$ \\
\hline Other & $11(6.1)$ \\
\hline Cerebral palsy & $4(2.2)$ \\
\hline Trisomy 21 & $2(1.1)$ \\
\hline Lung disease (bronchiectasis) & $1(0.6)$ \\
\hline Metabolic and mitochondrial disease & $4(2.2)$ \\
\hline Chest wall disease & $4(2.2)$ \\
\hline
\end{tabular}

in Figure 3; subjects with DMD used significantly higher insufflation $P=.02$ and exsufflation pressures $P=.009$ compared to those with SMA. We found no correlation between age and settings.

CPF was measurable in 114 subjects, and median (IQR) CPF was $60 \mathrm{~L} / \mathrm{min}(10-100 \mathrm{~L} / \mathrm{min}) ; 16$ subjects were unable to perform the maneuver. CPF was not measured in 51 subjects ( 17 had tracheostomies, 4 were initiated while acutely ill, and 30 were completely dependent on noninvasive ventilation. We found no correlation between pressure settings and unassisted CPF $(P>.050)$.

During the study period, 29 subjects died. One device was removed because the subject was not using it. Another subject stopped due to pneumothorax related to pleuroparenchymal fibroelastosis; this subject was on noninvasive ventilation, and the pneumothorax was not thought to be directly related to MI-E use. Two subjects did not tolerate the device. The first of these 2 subjects stopped due to severe abdominal distention despite using a low insufflation pressure of $16 \mathrm{~cm} \mathrm{H}_{2} \mathrm{O}$ and an exsufflation pressure of $25 \mathrm{~cm} \mathrm{H}_{2} \mathrm{O}$; this subject had longstanding issues with ab-
Table 2. Mechanical Insufflation-Exsufflation Characteristics

\begin{tabular}{|c|c|}
\hline \multicolumn{2}{|l|}{ Ventilatory support } \\
\hline Tracheostomy & 17 \\
\hline Noninvasive ventilation & 156 \\
\hline None & 8 \\
\hline \multicolumn{2}{|l|}{ MI-E interface } \\
\hline Mask & 163 \\
\hline Tracheostomy & 17 \\
\hline Mouthpiece & 1 \\
\hline \multicolumn{2}{|l|}{ MI-E mode } \\
\hline Basic automatic & 85 \\
\hline Timed auto & 82 \\
\hline Triggered auto & 6 \\
\hline Manual & 8 \\
\hline \multicolumn{2}{|l|}{ Group MI-E settings } \\
\hline Insufflation pressure, $\mathrm{cm} \mathrm{H}_{2} \mathrm{O}$ & $25(23-30)$ \\
\hline Exsufflation pressure, $\mathrm{cm} \mathrm{H}_{2} \mathrm{O}$ & $-35(-30$ to -40$)$ \\
\hline Insufflation time, $\mathrm{s}$ & $1.5(1.3-1.7)$ \\
\hline Exsufflation time, $\mathrm{s}$ & $1.8(1.5-2.0)$ \\
\hline Pause, s & $1.5(1.3-2.0)$ \\
\hline \multicolumn{2}{|l|}{ Adult MI-E settings } \\
\hline Insufflation pressure, $\mathrm{cm} \mathrm{H}_{2} \mathrm{O}$ & $28(25-30)$ \\
\hline Exsufflation pressure, $\mathrm{cm} \mathrm{H}_{2} \mathrm{O}$ & $-35(-32$ to -40$)$ \\
\hline Insufflation time, s & $1.5(1.3-1.8)$ \\
\hline Exsufflation time, s & $2.0(1.5-2.4)$ \\
\hline Pause, s & $1.5(1.3-2.0)$ \\
\hline \multicolumn{2}{|l|}{ Pediatric MI-E settings } \\
\hline Insufflation pressure, $\mathrm{cm} \mathrm{H}_{2} \mathrm{O}$ & $25(20-28)$ \\
\hline Exsufflation pressure, $\mathrm{cm} \mathrm{H}_{2} \mathrm{O}$ & $-30(-25$ to -35$)$ \\
\hline Insufflation time, $\mathrm{s}$ & $1.3(1.3-1.7)$ \\
\hline Exsufflation time, s & $1.5(1.4-1.6)$ \\
\hline Pause, s & $1.5(1.2-1.5)$ \\
\hline \multicolumn{2}{|l|}{ Inspiratory flow profile, $\%$} \\
\hline High & 100 \\
\hline Medium & 0 \\
\hline Low & 0 \\
\hline \multicolumn{2}{|l|}{ Oxygen, $\%$} \\
\hline Yes & 0 \\
\hline No & 100 \\
\hline \multicolumn{2}{|l|}{ Oscillations } \\
\hline Insufflation & 3 \\
\hline Exsufflation & 3 \\
\hline Insufflation and exsufflation & 2 \\
\hline
\end{tabular}

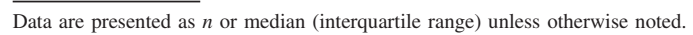
MI-E $=$ mechanical insufflation-exsufflation

dominal distention prior to the initiation of MI-E. The other subject discontinued due to feeling uncomfortable with an insufflation pressure of $15 \mathrm{~cm} \mathrm{H}_{2} \mathrm{O}$ and a sensation of suffocation with exsufflation $\left(-15 \mathrm{~cm} \mathrm{H}_{2} \mathrm{O}\right)$, despite individualized settings and adjustments. Three subjects transferred care to other centers.

Information prospectively recorded by the home care service and maintenance team reported that our subjects made up $<1 \%$ of all after-hours calls received within a 


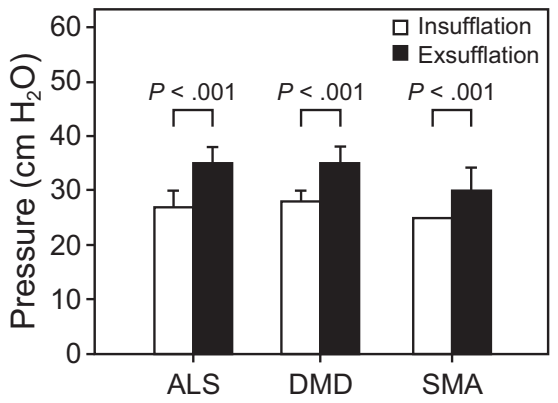

Fig. 3. Mean insufflation pressures and exsufflation pressures for subjects with amyotrophic lateral sclerosis (ALS, $n=23$ ), Duchenne muscular dystrophy (DMD, $n=39$ ), and spinal muscular atrophy (SMA, $n=34$ ). Greater exsufflation pressures than insufflation pressures were used for all subject groups (2-tailed $t$ test).

Table 3. Group Adherence to Mechanical Insufflation-Exsufflation

\begin{tabular}{lc}
\hline \hline Days used, \% & $60(13.5-100)$ \\
Treatments per day, no. & $1.8(1.1-3.3)$ \\
Total treatment time, min & $23.0(6.4-50.0)$ \\
Session treatment time, $\min$ & $2.3(1.1-6.0)$
\end{tabular}

$\overline{\text { Data are presented as }}$ median (interquartile range).

2-y period. Calls received during office hours were to report change of address and changes to the device setting. Only 3 after-hours calls required intervention for circuit problems, device suction, and to see if the device was working. Two visits were made, and no issues with the device were found. There were no calls to the home care service regarding practical application of the device. No devices failed mechanically.

We received downloads for $76 \%$ of subjects (137 of 181 subjects). Download data were not available in $24 \%$ of subjects because not all subjects had their device for $>1 \mathrm{y}$, and therefore a download had not been performed. Results are shown in Table 3. Sixty-four percent of subjects with tracheostomies used MI-E on a daily basis versus $31 \%$ who did not have a tracheostomy. The only subject group to use the device on a daily basis was those with SMA type I. Conversely, $22 \%$ of subjects used the device for $<10 \%$ of the total days available on download. In this group of low users, only 1 subject had a tracheostomy; 4 subjects had a CPF of $100-160 \mathrm{~L} / \mathrm{min}$, whereas all of the others had a $\mathrm{CPF}<100 \mathrm{~L} / \mathrm{min}$ and 6 were unable to perform a CPF manuever. Download adherence was not related to a specific diagnostic group.

\section{Discussion}

We report the largest single-center experience of MI-E in the clinical setting. Although this is a diverse group of subjects with an ineffective cough, we believe that our results will be a record of practice to help other teams reach consensus. We generally used greater exsufflation pressures than insufflation pressures. Subjects with tracheostomies were more likely than those without to use the device on a daily basis. CPF did not correlate with the pressures required for an effective cough.

\section{Limitations of the Study}

Previous studies have reported improvements in $\mathrm{S}_{\mathrm{pO}_{2}}$, avoidance of hospitalizations, and invasive techniques for mucus removal, along with decreased work of breathing using MI-E. 11,18,25,26 We did not capture any data on hospitalizations or avoidance of hospitalizations in our group, and therefore, it is impossible to know how many respiratory tract infections were prevented. We also were not able to measure any changes in CPF because the device we used does not have this feature.

Our center is a highly specialized sleep and respiratory care service. Many of our subjects were using ventilatory support. Therefore, our results may not be extrapolated to patients who are not using ventilatory support. That said, most patients who use MI-E devices are likely to need ventilatory support at some time. We hope that by providing detailed information on settings we can reach out to other teams and the wider community to help plan comprehensive care.

\section{Significance of Findings}

Settings. Like Hov and co-workers ${ }^{21}$ we found the automatic mode was the most commonly used mode in our sample. We also used greater exsufflation pressures than insufflation pressures, and there was a tendency to increase pressures with age in the pediatric population. Our work adds to the literature by providing information about pressure settings in the adult population and comparing settings in 3 subject groups. Median insufflation and exsufflation settings were similar in subjects with DMD and ALS; subjects with SMA used significantly lower settings than those with DMD. One explanation for this may be that the subjects with SMA were younger at initiation than those with DMD. Our subjects' median (IQR) pressure settings were $25(23-30) \mathrm{cm} \mathrm{H}_{2} \mathrm{O}$ for insufflation and -35 ( -30 to -40$) \mathrm{cm} \mathrm{H}_{2} \mathrm{O}$ for exsufflation. Pressures may seem lower than described in bench studies, ${ }^{7,9}$ but we used a NippyClearway device, which has a pressure line at the mask that delivers the set pressure on the machine ${ }^{14,27}$ and thus eliminates the typical pressure drop across circuitry reported by others. ${ }^{28}$ This is a more accurate way of ensuring that the pressure set on the machine is delivered to the subject at the mask. ${ }^{27,28}$ Knowledge regarding optimum time settings for insufflation, exsufflation, and pause 
is mainly experience-based. Our settings did have a greater insufflation time of $1 \mathrm{~s}$ as recommended for equilibrium between insufflation pressure and alveolar pressure. ${ }^{8}$ However, in contrast to bench studies, our insufflation time was shorter than our exsufflation time (1.5 [1.3-1.7] s vs 1.8 [1.5-2.0] s). Despite this, all of our subjects' settings were titrated so that they could clear secretions. Our insufflation time was slightly less than our exsufflation time, and we also used a greater exsufflation pressure. The combination of a high exsufflation pressure and shorter exsufflation time creates a high air-flow bias, and therefore did not cause secretion retention. All subjects' inspiratory flow profiles were set to high. This is also likely to contribute to an expiratory air-flow bias because our exsufflation pressures were greater than our insufflation pressure. However, with new evidence emerging from both a bench study, ${ }^{10}$ and flexible transnasal fiber-optic laryngoscopy during MI-E, 29,30 it is clear that more attention needs to be paid to insufflation flow and insufflation pressures. A key implication for clinicians is that some bulbar ALS patients are unlikely to benefit from high pressures and flows and may not tolerate MI-E if they have spasticity of the upper airway.

Cough Peak Flow. No study has evaluated CPF with respect to insufflation and exsufflation pressure settings. One possible explanation for this could be that the lower the unassisted $\mathrm{CPF}$, the greater the insufflation and exsufflation pressures required to generate an effective cough. On the other hand, the individual may have a low CPF but a compliant chest wall, which would mean that lower driving pressures are required to deliver an effective CPF. Indeed, Mellies and Goebel ${ }^{31}$ showed that delivering a deep breath in to a maximum insufflation capacity did not produce the greatest CPF. Lacombe et $\mathrm{al}^{32}$ reported no benefit in the addition of MI-E when subjects could generate high CPF with a maximum insufflation combined with a manual assisted cough. It is difficult to have a protocol dictating one setting for all patients, thus we advocate for an individualized prescription. Further prospective studies are warranted to evaluate the relationship between CPF and settings.

Adherence. Expert consensus reports suggest that use of MI-E in very weak individuals is a priority. ${ }^{3,4}$ When the $\mathrm{CPF}$ is $\sim 160 \mathrm{~L} / \mathrm{min}$, it is thought that the best device to improve cough efficacy is an MI-E device. ${ }^{14,33,34}$ The median CPF was $60 \mathrm{~L} / \mathrm{min}$ in our subject group with an interquartile range of $10-100 \mathrm{~L} / \mathrm{min}$, and $97 \%$ of our subject group received ventilatory support. We therefore believe that we provided devices to the subjects who needed it most, based on current guidelines. ${ }^{1,3-6}$

We report 137 adherence downloads. This is the largest report of use. The median daily use was $60 \%$ of the days downloaded. Unlike others, we did not ask our subjects in detail why they used their devices as they did. Subjects with a tracheostomy or a diagnosis of SMA type I were more likely to use the device daily. One explanation for this is that individuals with tracheostomies are likely to produce secretions daily. The use of MI-E through a tracheostomy has been reported as less irritating, less painful, less tiring, and less uncomfortable, ${ }^{35}$ as well as more effective, than endotracheal suctioning, which can be uncomfortable. ${ }^{36}$ This may be one of the reasons why a higher daily adherence to the use of MI-E was noted in our tracheostomy group. In a survey of 37 subjects with NMD who used MI-E at home, $46 \%$ used MI-E daily and 27\% weekly. ${ }^{22}$ We also found that $22 \%$ of subject downloads had low usage $(<10 \%$ of total days downloaded). From our data we cannot conclude a reason for low usage. The group had a mixture of diagnoses, and not all subjects had preserved pulmonary function; however, upon review, all had a low secretion burden. As a barrier to use, it has been suggested that domiciliary MI-E medicalizes the home, ${ }^{37}$ despite perceived benefits of MI-E for physical, social, and emotional aspects of living. ${ }^{38}$ Negative impacts were greatest for those parents who were sole operators of the device, who frequently reported disruption to lifestyle. ${ }^{37}$ Our view is that the daily presence of secretions is more likely to drive daily usage than low CPF. In individuals with low adherence, the barriers to use and the related consequences should be explored.

We asked subjects to use the device daily to check for secretions, to provide a chest wall stretch, and to remain familiar with the device. Some subjects may feel familiar with the device quickly, or they may not have secretions daily, or they may use a ventilator that provides a chest wall stretch. In this situation, perhaps the treatment plan should be different and less intensive, or the device should be available via a rapid-access program provision when needed, given that these individuals only require the device when secretions are a problem. Pragmatically, MI-E use when required is more sensible because we should avoid overburdening individuals with unnecessary medical interventions. ${ }^{39}$ However, it is important to have the right equipment available to individuals to prevent prolonged ineffective secretion-clearance sessions and respiratory tract infections. Requirements should be reassessed regularly, especially in those with progressive disorders.

Training and Support. Lack of consistent advice and education has been seen as a barrier to use of MI-E in children. ${ }^{38}$ Another study investigating the home use of MI-E in subjects with ALS reported that health professionals need to be mindful of individual and social aspects of implementing an MI-E device in the individual's home environment. Proper instruction and practical training to instill confidence in how to use the device, plus trust and 
continuity among carers, are important factors for successful implementation. ${ }^{40}$ To facilitate this in our group, we had a comprehensive in-house training program.

Complications. Reported adverse effects of MI-E include pneumothorax, ${ }^{26}$ nausea, bradycardia, tachycardia, and abdominal distention.$^{41}$ In children, thoracic wall discomfort, crying, and agitation in response to treatment with MI-E have been reported. ${ }^{13}$ Like others, ${ }^{26}$ we have experienced complications with MI-E. Our process for provision of the device is highly selective. All subjects were assessed and trialed with the device prior to home use. Only 2 subjects returned the device because they could not tolerate it; one subject had existing abdominal symptoms, and these were exacerbated; the other could not tolerate pressures higher than their ventilator inspiratory positive airway pressure. One subject stopped due to a pneumothorax, which was managed medically, and 3 other subjects who developed pneumothorax continue to use the device with lower pressure settings and regular monitoring.

\section{Conclusions}

In this large, single-center review of MI-E practice, we have demonstrated that good adherence can be achieved with a comprehensive education program. MI-E devices were provided to the weakest subjects with a CPF $<160$ $\mathrm{L} / \mathrm{min}$, which is in line with current guidelines. We used greater exsufflation pressures than insufflation pressures, along with insufflation times less than exsufflation times. Predicting which patients will exhibit good adherence is difficult, but our results indicate that patients who produce secretions daily are more likely to use MI-E daily.

\section{ACKNOWLEDGMENTS}

The authors acknowledge Adam Rochester and Caroline Davies-Jones for their assistance in the initiation of subjects with MI-E devices.

\section{REFERENCES}

1. Toussaint M, Chatwin M, Gonzales J, Berlowitz DJ, ENMC Respiratory Therapy Consortium. 228th ENMC International Workshop: Airway clearance techniques in neuromuscular disorders. Naarden, The Netherlands, 3-5 Mar, 2017. Neuromuscul Disord 2018;28(3): 289-298.

2. Chatwin M, Toussaint M, Goncalves MR, Sheers N, Mellies U, Gonzales-Bermejo J, et al. Airway clearance techniques in neuromuscular disorders: a state of the art review. Respir Med 2018;136: 98-110.

3. Bott J, Blumenthal S, Buxton M, Ellum S, Falconer C, Garrod R, et al. Guidelines for the physiotherapy management of the adult, medical, spontaneously breathing patient. Thorax 2009;64(Suppl 1): i1-i51.

4. Hull J, Aniapravan R, Chan E, Chatwin M, Forton J, Gallagher J, et al. British Thoracic Society guideline for respiratory management of children with neuromuscular weakness. Thorax 2012;67(Suppl 1):i1-i40.
5. Birnkrant DJ, Bushby K, Bann CM, Alman BA, Apkon SD, Blackwell A, et al. Diagnosis and management of Duchenne muscular dystrophy, part 2: respiratory, cardiac, bone health, and orthopaedic management. Lancet Neurol 2018;17(4):347-361.

6. Finkel RS, Mercuri E, Meyer OH, Simonds AK, Schroth MK, Graham RJ, et al. Diagnosis and management of spinal muscular atrophy: part 2: pulmonary and acute care; medications, supplements and immunizations; other organ systems; and ethics. Neuromuscul Disord 2018;28(3):197-207.

7. Guerin C, Bourdin G, Leray V, Delannoy B, Bayle F, Germain M, et al. Performance of the cough assist insufflation-exsufflation device in the presence of an endotracheal tube or tracheostomy tube: a bench study. Respir Care 2011;56(8):1108-1114.

8. Striegl AM, Redding GJ, Diblasi R, Crotwell D, Salyer J, Carter ER. Use of a lung model to assess mechanical in-exsufflator therapy in infants with tracheostomy. Pediatr Pulmonol 2011;46(3):211-217.

9. Gomez-Merino E, Sancho J, Marin J, Servera E, Blasco ML, Belda FJ, et al. Mechanical insufflation-exsufflation: pressure, volume, and flow relationships and the adequacy of the manufacturer's guidelines. Am J Phys Med Rehabil 2002;81(8):579-583.

10. Volpe MS, Naves JM, Ribeiro GG, Ruas G, Amato MBP. Airway clearance with an optimized mechanical insufflation-exsufflation maneuver. Respir Care 2018;63(10):1214-1222.

11. Chatwin M, Bush A, Simonds AK. Outcome of goal-directed noninvasive ventilation and mechanical insufflation/exsufflation in spinal muscular atrophy type I. Arch Dis Child 2011;96(5):426-432.

12. Vianello A, Corrado A, Arcaro G, Gallan F, Ori C, Minuzzo M, et al. Mechanical insufflation-exsufflation improves outcomes for neuromuscular disease patients with respiratory tract infections. Am J Phys Med Rehabil 2005;84(2):83-88.

13. Miske LJ, Hickey EM, Kolb SM, Weiner DJ, Panitch HB. Use of the mechanical in-exsufflator in pediatric patients with neuromuscular disease and impaired cough. Chest 2004;125(4):1406-1412.

14. Mustfa N, Aiello M, Lyall RA, Nikoletou D, Olivieri D, Leigh PN, et al. Cough augmentation in amyotrophic lateral sclerosis. Neurology 2003;61:1285-1287.

15. Bach JR, Goncalves MR, Hamdani I, Winck JC. Extubation of patients with neuromuscular weakness: a new management paradigm. Chest 2010;137(5):1033-1039.

16. Goncalves MR, Honrado T, Winck JC, Paiva JA. Effects of mechanical insufflation-exsufflation in preventing respiratory failure after extubation: a randomized controlled trial. Crit Care 2012;16(2):R48.

17. Vitacca M, Paneroni M, Trainini D, Bianchi L, Assoni G, Saleri M, et al. At home and on demand mechanical cough assistance program for patients with amyotrophic lateral sclerosis. Am J Phys Med Rehabil 2010;89(5):401-406.

18. Winck JC, Goncalves MR, Lourenco C, Viana P, Almeida J, Bach JR. Effects of mechanical insufflation-exsufflation on respiratory parameters for patients with chronic airway secretion encumbrance. Chest 2004;126(3):774-780.

19. Tzeng AC, Bach JR. Prevention of pulmonary morbidity for patients with neuromuscular disease. Chest 2000;118(5):1390-1396.

20. Sancho J, Bures E, de La Asunción S, Servera E. Effect of highfrequency oscillations on cough peak flows generated by mechanical in-exsufflation in medically stable subjects with amyotrophic lateral sclerosis. Respir Care 2016;61(8):1051-1058.

21. Hov B, Andersen T, Hovland V, Toussaint M. The clinical use of mechanical insufflation-exsufflation in children with neuromuscular disorders in Europe. Paediatr Respir Rev 2018;27:69-73.

22. Mahede T, Davis G, Rutkay A, Baxendale S, Sun W, Dawkins HJS, et al. Use of mechanical airway clearance devices in the home by people with neuromuscular disorders: effects on health service use and lifestyle benefits. Orphanet J Rare Dis 2015;10:54. 


\section{LONG-TERM MI-E USE IN NMD}

23. Bianchi C, Baiardi P. Cough peak flows: standard values for children and adolescents. Am J Phys Med Rehabil 2008;87(6):461-467.

24. Szeinberg A, Tabachnik E, Rasshed N, McLaughlin FJ, Englan S, Bryan CA, et al. Cough capacity in patients with muscular dystrophy. Chest 1988;94(6):1232-1235.

25. Chatwin M, Simonds A. The addition of mechanical insufflationexsufflation shortens airway clearance sessions in neuromuscular patients with a chest infection. Respir Care 2009;54(11):1473-1479.

26. Suri P, Burns S, Bach J. Pneumothorax associated with mechanical insufflation-exsufflation and related factors. Am J Phys Med Rehabil 2008;87(11):951-955.

27. Chatwin M, Ross E, Hart N, Nickol AH, Polkey MI, Simonds AK. Cough augmentation with mechanical insufflation/exsufflation in patients with neuromuscular weakness. Eur Respir J 2003;21(3):502508.

28. Fauroux B, Guillemot N, Aubertin G, Nathan N, Labit A, Clément A, et al. Physiologic benefits of mechanical insufflation-exsufflation in children with neuromuscular diseases. Chest 2008;133(1):161168.

29. Andersen T, Sandnes A, Brekka AK, Hilland M, Clemm H, Fondenes $\mathrm{O}$, et al. Laryngeal response patterns influence the efficacy of mechanical assisted cough in amyotrophic lateral sclerosis. Thorax 2017;72(3):221-229.

30. Andersen T, Sandnes A, Hilland M, Halvorsen T, Fondenes O, Heimdal $\mathrm{JH}$, et al. Laryngeal response patterns to mechanical insufflationexsufflation in healthy subjects. Am J Phys Med Rehabil 2013; 92(10):920-929.

31. Mellies U, Goebel C. Optimum insufflation capacity and peak cough flow in neuromuscular disorders. Ann Am Thorac Soc 2014;11(10): $1560-1568$.

32. Lacombe M, Del Amo Castrillo L, Bore A, Chapeau D, Horvat E, Vaugier I, et al. Comparison of three cough-augmentation techniques in neuromuscular patients: mechanical insufflation combined with manually assisted cough, insufflation-exsufflation alone and insufflation-exsufflation combined with manually assisted cough. Respiration 2014;88(3):215-222

33. Toussaint M, Boitano LJ, Gathot V, Steens M, Soudon P. Limits of effective cough-augmentation techniques in patients with neuromuscular disease. Respir Care 2009;54(3):359-366.

34. Bach JR, Saporito RRT. Criteria for extubation and tracheostomy tube removal for patients with ventilatory failure. Chest 1996;110: 1566-1571.

35. Garstang SV, Kishblum SC, Wood KE. Patient preference for inexsufflation for secreation management with spinal cord injury. J Spinal Cord Med 2000;23(2):80-85.

36. Sancho J, Servera E, Vergara P, Marin J. Mechanical insufflationexsufflation vs. tracheal suctioning via tracheostomy tubes for patients with amyotrophic lateral sclerosis: a pilot study. Am J Phys Med Rehabil 2003;82(10):750-753.

37. Moran FC, Spittle AJ, Delany C. Lifestyle implications of home mechanical insufflation-exsufflation for children with neuromuscular disease and their families. Respir Care 2015;60(7):967-974.

38. Travlos V, Drew K, Patman S. The value of the CoughAssist in the daily lives of children with neuromuscular disorders: experiences of families, children and physiotherapists. Dev Neurorehabil 2015;1-6.

39. Dobler CC. Too much or too little medicine? Overdiagnosis, underdiagnosis, overtreatment and undertreatment in respiratory diseases. Breathe 2019;15(1):2-3.

40. Siewers V. Experiences with using mechanical in-exsufflation in amyotrophic lateral sclerosis Eur J Physiother 2013;15:201-207.

41. Bach JR. Update and perspective on noninvasive respiratory muscle aids. Part 2: the expiratory aids. Chest 1994;105(5):1538-1544.

This article is approved for Continuing Respiratory Care Education credit. For information and to obtain your CRCE

(free to AARC members) visit www.rcjournal.com 